\title{
Queremos trabajar: iCUPO LABORAL TRANS YA! A cuatro años de la ley en la Provincia de Buenos Aires
}

\author{
Alba Rueda \\ Activista trans, Integrante de Mujeres Trans Argentina / Centro Cultural de la Cooperación "Floreal Gorini". \\ Departamento de Género y Comunicaciones / Observatorio de la Discriminación del INADI (Instituto Nacional contra \\ la Discriminación, la Xenofobia y el Racismo), Argentina \\ alba.rueda5000@gmail.com
}

A siete años de aprobada la Ley de Identidad de Género, a cuatro años de aprobada la Ley de Cupo Laboral Trans en la Provincia de Buenos Aires, y otras tantas resoluciones municipales que se sumaron a la propuesta de la inserción laboral de travestis y trans, los planteos se dirigen a saber si cambió la inclusión trans en empleos formales, si el marco normativo repara este reclamo histórico de vulnerabilidad, a la vez que interroga sobre las estrategias para asegurar una vida digna en contextos neoliberales.

Suena paradójico googlear "cupo trans" y encontrarnos con numerosas noticias que hablan del mapa de leyes del cupo laboral, de la presentación de los proyectos de ley, de que existen leyes de cupo trans en varias provincias argentinas pero que no se aplican. ¿Por qué sucede esto? Porque no hay reglamentación de cupo en ningún lugar donde se presentó como ley provincial, ni provincia alguna que haya creado un listado oficial de aplicantes al cupo laboral en empleos públicos, ni situación de que hayan ingresado real y efectivamente compañeres trans como parte de una política pública. Es decir, la agenda trans respecto del empleo parece avanzar en todo el país pero solo de manera formal, sin aplicación.

Distingamos, entonces, el trabajo que se llevó adelante desde las organizaciones sociales en experiencias locales, donde en el mejor de los casos se logra la aprobación en algún municipio o provincia, y tras ello se incorporan tres o cuatro compañeras trans a un puesto laboral. La aprobación de estas leyes no buscó un carácter testimonial, sino que fue promovida desde la búsqueda de justicia social, de universalizar el acceso al empleo formal de la población travesti trans, un "equis" por ciento a los empleos públicos como parte de las políticas afirmativa de derechos humanos para nuestra población.

Es decir, se desarrollaron políticas de goteo y amiguismos, pero estas no son siquiera un consuelo, son una provocación, puesto que las personas destinatarias del cupo no lograron en su trayecto de vida el acceso a los derechos económicos, sociales y culturales. Los testimonios, encuestas, informes y relevamientos dan cuenta de la extrema vulnerabilidad estructural que viven las personas trans en Argentina, entonces iqué herramientas nos quedan frente a estas mezquindades, donde el estado desconoce y omite la aplicación del derecho?

\section{ENCUADRES Y CONTEXTOS}

Para abordar estos temas, consideremos el planteo del activista trans y profesor en leyes Dean Spade, en su libro Una vida normal (2015), donde aborda la desigualdad social de la población y la vincula a 
una desintegración estructural del sistema económico, político y estatal. Según su perspectiva, una ley de carácter reformista no puede resolver esta problemática porque el esquema propio del sistema de justicia, $\mathrm{y}$ la justicia administrativa, estructuran una desigualdad que no permite que todas las personas puedan ejercer los derechos de manera plena. Entonces, la criminalización, la exclusión de los derechos a la migración, la pobreza y las condiciones de vida de personas son la contracara a los propios valores liberales como la igualdad y libertad.

Para mostrar esta exclusión, Spade pone el foco en el goteo y desplazamiento a poblaciones que circulan en el sistema judicial y administrativo de justicia, donde no hay una universalidad de acceso a los derechos formales. El autor busca desentrañar "lo que los regímenes jurídicos hacen y no lo que dicen que hacen. Nos fijamos más en cómo se distribuye la vulnerabilidad entre poblaciones, no sólo entre individuos" (Spade, 2015, p. 45). Los planteos formales de acceso se encuentran tamizados, mediados por la burocracia estatal, que evalúa quién es el sujeto que reclama estos derechos, eligiendo y seleccionando a partir de cuestiones de clase, etnia y sexo. Entonces, la vulnerabilidad estructural se encuentra en el propio estado racista, clasista y xenófobo, a pesar de sus discursos jurídicos de máximas libertarias, estos tapan la distribución de la desigualdad y vulnerabilidad.

Al seguir la Critical Race Theory, Spade acerca un análisis trans crítico sobre los modelos jurídicos y lo extiende al ámbito del derecho administrativo, ilustrando cómo los modos de gobernanza administrativa producen lo que terminamos asumiendo como identidades naturales o preexistentes (Spade, 2015, p. 47).

Si hilvanamos estos planteos, de lo que sucede con el cupo laboral y los argumentos críticos al reformismo legal, podemos considerar nuestras experiencias de militancia y luchas trans en este lado del planeta. La ley de Identidad de Género (LID) aprobada en mayo de 2012, constituye para las organizaciones sociales uno de los logros más significativos a nivel social. El reconocimiento a la identidad de género basado en el carácter del sujeto en la decisión sobre su trayecto de vida, es una respuesta a las instituciones médicas o judiciales que evaluaban la salud mental y administraban el control de la respuesta estatal en cirugías y tratamientos hormonales. Asimismo, se establece el acceso a la salud integral (artículo 11) teniendo en cuenta intervenciones quirúrgicas totales y/o parciales, y tratamientos de hormonización, en caso que cualquier persona lo solicite para adecuar su cuerpo a su identidad de género. También, resguarda el trato digno de toda persona trans independientemente de su rectificación registral de documentos (artículo 12), especialmente cuando son menores de dieciocho años. Así, las militancias travesti y trans logran aprobar una ley que ubica al estado en función administrativa con el fin de resguardar el derecho a la identidad de género.

Por la amplia legitimación de las organizaciones sociales, el al to impacto social que tuvo, y por ser la primera ley que avanza en nuevos estándares de derechos hacia las personas trans en la América del Sur, se consideró en aquellos años, la ley más avanzada en derechos humanos para personas trans.

Desde esta perspectiva, la agenda política de las organizaciones sociales no está limitada por un engaño liberal donde el sistema político lava las culpas con un falso igualitarismo formal. Se trata de espacios de confrontación política donde la desigualdad de fuerzas da cuenta del enorme esfuerzo de los movimientos sociales por lograr un marco normativo que proteja la vida o mejore las condiciones de vida de las personas trans.

Esto permite un mensaje de inclusión social. Desde entonces las personas trans contamos con una ley donde ampararnos ante determinados obstáculos administrativos, consolidando al sujeto político trans. Este fortalecimiento se vio en la configuración de una agenda social amplia que involucra el reconocimiento de vulnerabilidades estructurales, como el acceso al empleo y la reparación estatal a la violencia institucional con la aplicación de los edictos policiales.

Asimismo, permitió que otras realidades travestis y trans puedan avanzar con reclamos que se asientan en el derecho a la identidad: reclamo por la feminidad travesti, de personas no binaries, son muestra de que el acrónimo LGBT no es un proyecto acabado. Finalmente, con el juicio de justicia por Diana Sacayán (2015), se logra dar un paso importante en el sistema judicial: por un lado, que se reconozca la trama de opresión y 
violencias que vive la población trans, condensada en el travesticidio-transfemicidio social; por otro lado, el reconocimiento de que el crimen a Diana se asentó en una violencia de género (agravante en el art 80 inc. 11) y estuvo basado en el odio a la identidad de género (art 80 inc. 4). ${ }^{1}$

Desde el año 2016, la marcha contra los travesticidios se expandió en todo el país, convocando a miles de personas a un reclamo colectivo, basado en un duelo público de personas trans y travestis que murieron por motivos evitables que involucran la ausencia de políticas públicas.

Es innegable que esa trama depende de contextos políticos, porque, desde el año 2015, vivimos gobiernos conservadores con discursos liberales, que no avanzan ni respetan lo que el sistema republicano permite. Estos gobiernos crearon nuevos mecanismos de criminalización a las disidencias, bajo intersecciones que rompen con la habitual represión general conocida. Hoy podemos ver a una trans siendo directora en el ministerio de seguridad, a la vez que un protocolo de detención para las fuerzas de seguridad refuerza la criminalización trans.

El narcomenudeo merece una atención particular ya que se desarrolla con vertiginosa celeridad, tipificado en la ley 26.052, donde se establece que la persecución del comercio ilícito de drogas a pequeña escala tiene un alcance material y territorial por jurisdicciones. Esto, además de criminalizar el consumo con expresiones vagas, como "escasas cantidades", incrementó de manera exponencial las causas por narcomenudeo, especialmente en personas trans vulneradas, sin atender la estructura del crimen organizado.

Estas normativas fortalecen la estigmatización a personas en prostitución callejera en distintas provincias. La trama de violencias es sofisticada y establece un valor diferencial a quienes accedimos a la universidad y/ o a empleos formales, lo que genera una profunda desigualdad con los sectores trans atravesados por otras variables de desigualdad, familia, educación, salud y empleo; para elles solo queda represión y mucho silencio.

Aquí encontramos un diálogo con el planteo de Spade y las realidades trans en Argentina: hay una violencia estructural que se dirige especialmente a sectores que son protegidos por leyes de igualdad y derechos humanos, pero que sufren el desplazamiento y la vulneración de sus derechos a través de la administración estatal y de justicia. El reconocimiento legal del derecho a la identidad se configura abstracto para la mayoría de las personas trans, sellando un sistema opresivo a través de un discurso liberal. Este anclaje de la colonización en el reconocimiento de la identidad implica un enorme desafío para las organizaciones sociales.

La propuesta de Spade implica trascender las políticas de reconocimiento e inclusión, siguiendo cuatro roles específicos para los proyectos de reforma jurídica:

1. Herramientas que mejoren la subsistencia de las personas trans: ayudando a participar en labores de organización de base.

2. Asistencia jurídica: convirtiendo las malas experiencias individuales en un entendimiento común de lucha colectiva.

3. Campañas de reforma jurídica: para producir oportunidades de organización que encabecen nuevos líderes.

4. Estrategias de reforma jurídica: pueden ser parte de las campañas cuyo objetivo sea exponer las contradicciones de los sistemas de control.

Estas cuatro funciones apuntan a una teoría para la organización del cambio centrada en una movilización masiva. También, introduce los cuatro pilares para la infraestructura de la justicia social (Spade, 2015, p. 57).

\section{SITUANDO EL CUPO TRANS}

Este planteo de Spade nos acerca a nuestras realidades bajo un prisma que advierte acerca de las políticas neoliberales y una mirada crítica hacia el reformismo jurídico en los valores neoliberales; pues, 
aún en contextos donde el mercado impera, considera que hay debates y tensiones que las organizaciones y los movimientos sociales llevan adelante, constituyendo un modelo emergente de experiencias en la resistencia.

En lo que sigue, nos proponemos considerar este problema del sistema judicial desde algunos márgenes, cuestionando los ámbitos e instituciones que funcionan como herramientas que conforman la legitimidad del sistema judicial. Estos espacios funcionan como usinas de saberes y difusión, donde las preguntas por las personas trans hablan de la parcialidad y asistencia que brindan en contextos de violencias estructurales.

El sistema judicial guarda uno de los criterios nodales en las sociedades democráticas y republicanas, resguardar la igualdad de derechos. Esa prerrogativa no se cumple para las travestis y trans en el sistema judicial, puesto que habitualmente las causas contra la violencia institucional quedaron analizadas en casos particulares y jugaron a favor de las fuerzas de seguridad. Los usos de los nombres propios en el sistema administrativo son respetados en la medida que obtengan los cambios de DNI, desconociendo el art.12 de la LID. La credibilidad de los testimonios de las personas trans es relativa a los trayectos sociales que desarrollen. Si están en prostitución entonces las categorías sospechosas adquieren fuerza estructurante de veracidad. Estas estructuras binarias suplantan las voces trans en relatos asimilacionistas donde el binarismo que estructura el derecho juega a favor de la parcialidad.

A la vez, una de las herramientas subsidiarias del sistema judicial son los saberes científicos, como la medicina forense. Desde estas perspectivas, las instituciones que desarrollan esos saberes sociales y científicos no consideran la ley de identidad de género. En el ingreso al campo y desarrollo de las ciencias médicas y sociales, faltan las voces de un grupo poblacional que forma parte de saberes críticos, ¿̨no surge la voluntad de buscar y crear herramientas que permitan incorporar saberes, experiencias trans en la constitución de saberes sociales? Inevitablemente el planteo involucra la democratización de las instituciones y la reformulación de herramientas fundamentales para romper la parcialidad del derecho.

Por su parte, los establecimientos psiquiátricos y psicológicos que desarrollan saberes sobre la salud mental, cuentan con una herramienta única en Suramérica para enfrentar un paradigma histórico en el campo: la patologización de las identidades trans y disidentes desde el modelo binario heterosexual. En contrapartida, cabe destacar que la Ley Nacional de Salud Mental (26.657 del 2010) explícitamente menciona "en ningún caso puede hacerse diagnóstico en el campo de la salud mental sobre la base exclusiva (...) a la elección o identidad sexual" (art. 3 inc. C), lo que constituye un paso importante para desestructurar dicha patologización a nuestras identidades y reescribir planteos reflexivos sin la base de sospechosas teorías biologicistas que naturalizan los géneros.

Los medios de comunicación también son saberes, empresas, políticas, que reforzaron la estigmatización social hacia nuestra comunidad. Por eso, la participación de voces trans en medios alternativos es fundamental para fortalecer el derecho a la comunicación de los pueblos, creando otros modos de representar las voces y las experiencias de vida de travestis y trans. En el juicio de Diana, las palabras travestis sobre el travesticidio social fueron fundamentales para mostrar la textura de la opresión que vivimos.

En el mismo sentido, las universidades, instituciones basadas en su autonomía y organización autárquica a través de un gobierno de docentes, no docentes y estudiantes, son espacios de reproducción de saberes y desarrollo de acciones en interacción con las sociedades. Como allí se concentra uno de los poderes más transformadores para la cultura y la remoción de estereotipos, nos preguntamos si cuentan con cátedras donde estén presentes las voces y saberes de la disidencia sexual, si hay una política universitaria específica para aumentar el ingreso de personas trans en las carreras.

Hay experiencias que avanzan en la diversidad, como la Universidad Nacional de La Plata, donde hay alguna/s docentes trans, baños sin distinción de géneros, pero no suman el cupo laboral trans, o herramientas efectivas para la participación en la trama del travesticidio social. Pronunciarse, conformar políticas activas acerca de la violencia institucional que vive la mayor parte de nuestra población trans es urgente. 
Lamentablemente, estos ámbitos e instituciones adoptan una posición de doble vara, donde acuerdan con derechos formales para las personas trans pero, en el momento de implementarlos, desplazan el conflicto al poder ejecutivo, sin considerar lo esenciales que son para la lucha contra la opresión que vivimos.

Lo que surge de este repaso es que la crítica al estado, o el contexto neoliberal que gobierna la región, no excluye un planteo crítico sobre las gobernanzas en las instituciones que hacen a la trama del sistema democrático. Los movimientos sociales logramos un debate e instalar el eje de los derechos de las disidencias sexuales, pero necesitamos avanzar en un diagnóstico crítico hacia estos ámbitos de poder y posibles alianzas para combatir el silencioso travesticidio y transfemicidio social. Mientras se relatan discursos de hechos aislados, presentados como "el caso", los mecanismos de criminalización por intersecciones llegan sutilmente a matarnos. La violencia es explícita y simbólica y encuentra su legitimación en el silencio de estos ámbitos de saberes, tanto académicos como de difusión.

El cupo trans permite poner un límite a estas violencias, no es el único camino, pero sí el que la población trans y sus organizaciones encontramos como herramienta de justicia social. La economía global y el poder transnacional no implica que tengamos que renunciar a todo, como pueblo tenemos nuestros compromisos por los derechos humanos. Los lugares que habitamos guardan nuestra memoria, desmantelando el colonialismo cisexual podremos habitar estos espacios, señalando nuestras ausencias resignificaremos la parcialidad que los constituye.

\section{REFERENCIAS BIBLIOGRÁFICAS}

Spade, D. (2015). Una vida normal. Barcelona: Bellaterra.

\section{Notas}

1. Diana Sacayán, destacada y reconocida activista travesti por los derechos humanos y de la lucha por el reconocimiento y la inclusión social del colectivo travesti en Argentina y en la región, entre los numerosos aportes que realizó están la campaña por la descriminalización de las travestis (2007), campaña por la ley de identidad de género (2012) y la ley de cupo laboral trans en la provincia de Buenos Aires (2015). Fue víctima de un travesticidio, el 11 de octubre de 2015, a sus 40 años. Por la conmoción en la comunidad travesti trans, se desarrolla una campaña de Justicia por Diana, llegando a una sentencia histórica, la primera en Sudamérica, que reconoce que se trató de un crimen de odio donde medió la violencia de género (Poder Judicial de la Nación, Tribunal oral en lo criminal y correccional Nro. 4 de la Capital Federal, CCC 62182/2015/TO1, 18/06/18). 